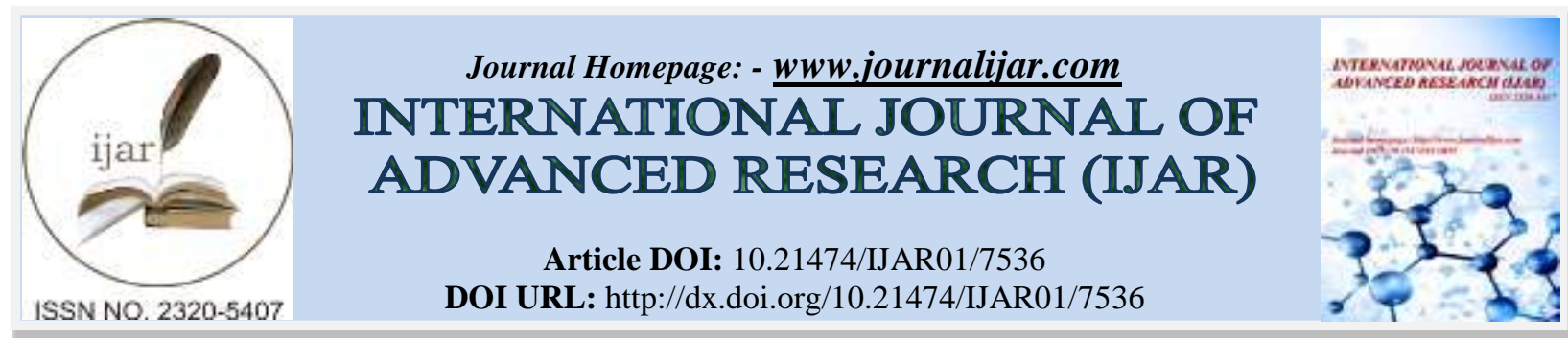

RESEARCH ARTICLE

\title{
PHARMACOGNOSTIC AND CHROMATOGRAPHIC PROFILING OF KHADIRA (ACACIA CATECHU
} (LINN.F.) WILLD).

"Dr. Vandana Venugopalan ${ }^{1}$, Dr. M. A Shajahan ${ }^{2}$ and Dr. V. C Indulekha ${ }^{3}$.

1. PG Scholar, Dept of Dravyagunavijnanam, Govt Ayurveda College, Thiruvananthapuram.

2. Professor, Dept of Dravyagunavijnanam, Govt Ayurveda College, Thiruvananthapuram.

3. Assistant Professor, Dept of Dravyagunavijnanam, Govt Ayurveda College, Thiruvananthapuram.

\section{Manuscript Info}

\section{Manuscript History}

Received: 11 June 2018

Final Accepted: 13 July 2018

Published: August 2018

Keywords:-

Khadira, , Acacia catechu (Linn.f.)

Willd, Pharmacognosy,, HPTLC.

\begin{abstract}
Introduction: Khadira is an Ayurvedic plant drug extensively used in Ayurvedic formulations. The source plant of Khadira, Acacia catechu (Linn.f.) Willd, is a moderate sized tree commonly growing in dry climatic conditions. Its heartwood is used for preparing Ayurvedic medicines. Ascertaining the identity, genuineness and purity of herbal drugs has an important role in the maintenance of the quality of Ayurvdic formulations. Hence the present work is taken up with an objective to standardize the heartwood of Khadira with detailed pharmacognostical and preliminary phytochemical standards.

Methods: Genuine heart wood of Acacia catechu (Linn.f.) Willd (Khadira) was collected from botanical garden of Government Ayurveda College, Poojappura, Thiruvananthapuram and shade dried. Macroscopic, physicochemical, chromatographic and heavy metal analysis was carried out as per ICMR procedures.

Result: Heart wood is light red to brownish red in colour, hard and even textured. On physicochemical evaluation water soluble extractive value was $6.1+0.047 \&$ alcohol soluble extractive value was $1.5+$ 0.032 . Heavy metals copper, cadmium, iron and lead level was found to be $0.1323+0.004,0.1346+0.012,7.888+0.061 \& 0.0685+0.043$ respectively. HPTLC was carried out with Toluene: Ethyl acetate: Formic acid as solvent system and 3 spots were obtained.

Conclusion: The results obtained in this study may help in standardization, identification and further research in Acacia catechu (Linn.f.) Willd (Khadira).
\end{abstract}

Copy Right, IJAR, 2018,. All rights reserved.

\section{Introduction:-}

Khadira is an Ayurvedic plant drug extensively used in Ayurvedic formulations. According to Caraka Samhitha (an ancient indian medical literature), Khadira is grouped under Kushaghna (that allaeviates skin diseases) and Udarda prasamana varga (that which relieves urticaria) based on its pharmacological properties. It is the herbal drug which is described as a drug of choice in the treatment of kushta (skin diseases) in classical Ayurvedic text books ${ }^{1}$. The source plant of Khadira is Acacia catechu (Linn.f.) Willd Acacia catechu (Linn.f.) Willd (Khadira) is a moderate sized tree mainly found in western ghats and Himalayan region ${ }^{2}$. It has an antimicrobial action and works as a mouth freshener diminishing bad breath. The drug is also observed to be an important ingredient in the formulations 
described in the treatment of skin diseases and oral diseases.

Khadira (Acacia catechu (Linn.f.) Willd) is a drug widely used in the pharmaceutical industry. It is an ingredient of several ayurvedic formulations like Khadirarishtam, Kanakabindvarishtam, Katakakhadiradi kashayam, Musalikhadiradi Kashayam etc ${ }^{3}$. Ascertaining the identity, genuineness and purity of herbal drugs has an important role in the maintenance of the quality of Ayurvdic formulations. This indicates the need to assess the genuineness of Khadira through pharmacognostical and phytochemical evaluation.

The objective of the present study is to evaluate the preliminary pharmacognostical phyto-chemical characters of the drug.

\section{Materials And Methods:-}

Sample collection- The sample drug Khadira (Acacia catechu (Linn.f.) Willd) was collected from herbal garden at Pharmacognosy Unit, Govt. Ayurveda College, Thiruvananthapuram and the sample was authenticated by Botanist, Drug Standardisation Unit, Govt. Ayurveda College Thiruvananthapuram, Kerala.

\section{Study settings}

Drug Standardisation Unit, Govt. Ayurveda College Thiruvananthapuram, Kerala.

1. Macroscopic evaluation- Fresh log of wood of Acacia catechu (Linn.f.) Willd was collected. The bark and the sapwood were removed and the heartwood was collected, shade dried and stored. The heartwood of Acacia catechu (Linn.f.) Willd was subjected to organoleptic evaluation and the observed macroscopic characters were recorded.

2. Microscopic evaluation- Microscopic evaluation is used for studying the histological features of transverse and longitudinal section of heartwood of Acacia catechu (Linn.f.) Willd. A portion of the heartwood was selected, soaked in water overnight and enough number of sections were taken. Transverse and longitudinal sections were prepared and stained as per standard procedure ${ }^{4}$. The sections were carefully transferred to a petri dish containing water and few thin sections that floated in water were selected. A stained section was carefully transferred on a clean glass slide using thin brush. With the help of forceps and needle a clean cover slip was gently placed over the section. Excess water was wiped with a blotting paper and the slide was placed on the stage of a digital microscope (Olympus digital- CS41, Japan, with CCD camera) for histological examination and direct images were taken.

\section{Preliminary physical and phytochemical evaluation}

Preliminary physicochemical and phytochemical analysis of genuine sample of the study were conducted. Physicochemical analysis included the evaluation of parameters like foreign matter, moisture content, ash values, fibre content, volatile oil content, sugar content and different extractive values, were done. It also included the qualitative tests for the detection of phenols, steroids, alkaloids, flavonoids, tannins and glycosides. The procedures were done as per procedures mentioned in ICMR $^{5}$ and Ayurvedic Pharmacopoeia of India ${ }^{6}$.

Heavy metal analysis by Atomic Absorption Spectroscopy and chromatographic techniques like TLC, HPTLC were also conducted.

\section{Results And Discussion:-}

The organoleptic evaluation and the microscopy of heartwood of Acacia catechu were conducted and the observations were noted. The data was analysed and results were interpreted from it.

\section{Macroscopic evaluation}

The observed macroscopical characters of heart wood of Acacia catechu (Khadira) are given in Table 1.

Table no.1 Macroscopic evaluation of heart wood of Acacia catechu

\begin{tabular}{|l|l|}
\hline Characters & Heart wood of Acacia catechu \\
\hline External surface & even textured, hard \\
\hline Colour & Light red to brownish red in colour \\
\hline Odour & Characteristic \\
\hline Taste & Astringent \\
\hline
\end{tabular}




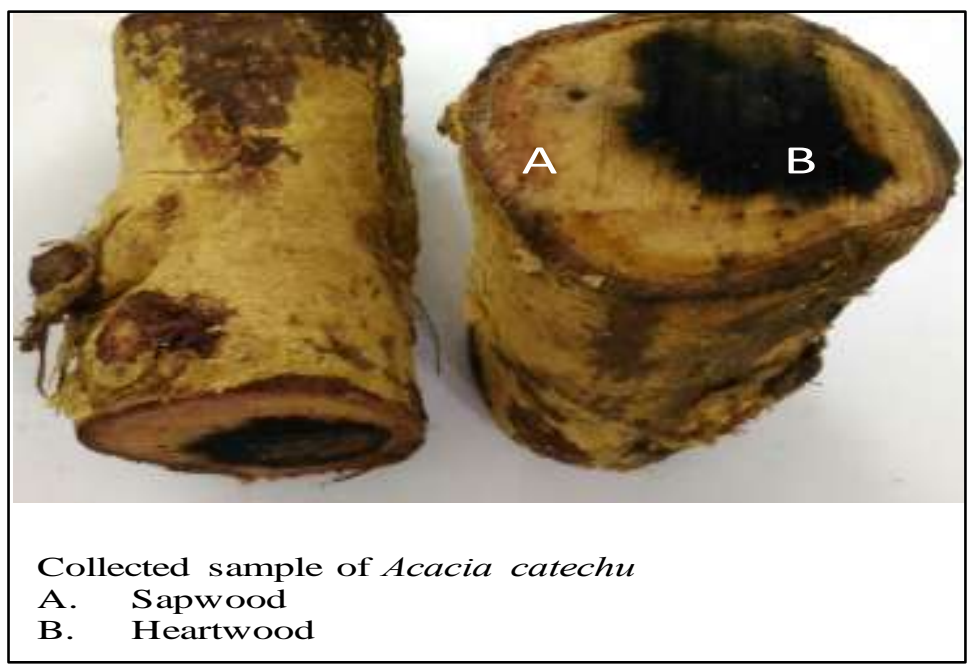

\section{Microscopic evaluation}

Fig 1:- Collected sample of Acacia catechu

The microscopic evaluation of Acacia catechu was carried out. Transverse section of heart wood showed vessels occurring isolated or in small groups. Vessels were often blocked with tyloses. Biseriate to multi serriate medullary rays were seen. Medullary rays were seen as vertically running linear bands. Multiseriate medullary rays and pitted border vessels were seen.

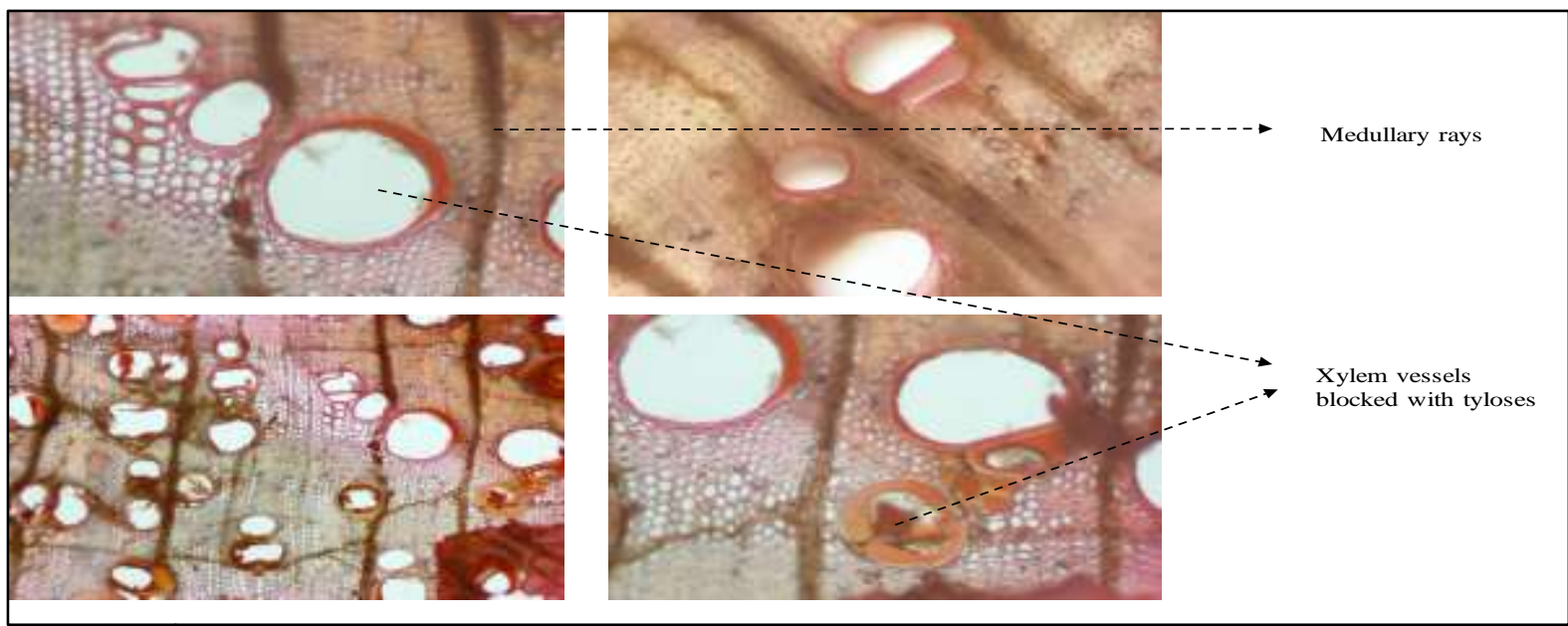

Figure 2:- Transverse section of heartwood of Khadira

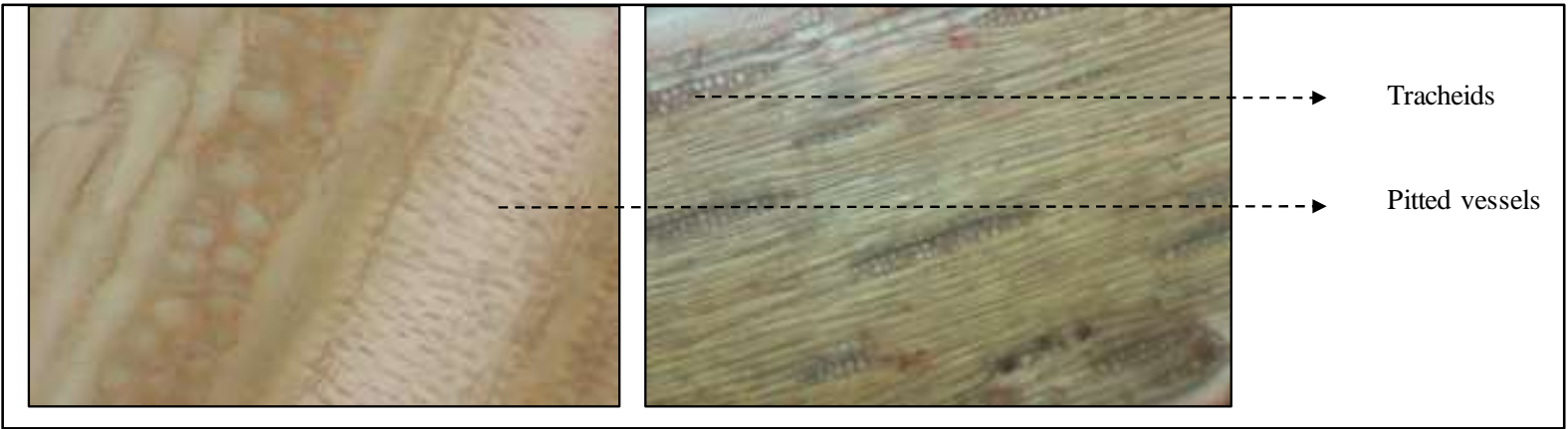

Figure 3:- Longitudinal section of heartwood of Khadira

\section{Results of preliminary physicochemical evaluation}

The screening of physical and phytochemical parameters of Acacia catechu were done as per the standard procedures. Physical characters like moisture content, total ash, acid insoluble ash, water extractive and alcohol soluble extractives were analysed. 
Table No.2 Preliminary physicochemical analysis

\begin{tabular}{|l|l|l|}
\hline SI No & Name of the experiment & Acacia catechu \\
\hline 1 & Foreign matter (\%) & Nil \\
\hline 2 & Moisture content (\%) & $10+/-0.335$ \\
\hline 3 & Volatile oil (\%) & Nil \\
\hline 4 & Total ash (\%) & $1.9+/-0.217$ \\
\hline 5 & Acid insoluble ash (\%) & $1.1+/-0.012$ \\
\hline 6 & Water soluble extractive (\%) & $6.1+/-0.047$ \\
\hline 7 & Alcohol soluble extractive (\%) & $1.5+/-0.032$ \\
\hline 8 & Fibre content (\%) & $45.24+/-1.56$ \\
\hline 9 & Sugar content & \\
& Reducing sugar $(\%)$ & $0.93+/-0.204$ \\
& Total sugar $(\%)$ & $1.20+/-0.276$ \\
\hline
\end{tabular}

\section{Results of preliminary phytochemical evaluation}

The ethanolic extractive obtained was subjected to qualitative analysis for identification of various plant constituents like steroids, phenols, alkaloids, flavonoids, tannins and results were summarized in Table No:3. The presence of various phytochemicals determines the pharmacological action and therapeutic potential of that plant. The preliminary phytochemical screening of heartwood showed the presence of different phytoconstituent groups such as steroid, flavonoid, saponin, alkaloid and tannin.

Table 3:- The results of qualitative chemical evaluation of alcoholic extract

\begin{tabular}{|l|l|l|}
\hline Sl no & Chemical constituent & Acacia catechu \\
\hline 1 & Steroid & - \\
\hline 2 & Flavonoid & ++ \\
\hline 3 & Phenol & + \\
\hline 4 & Alkaloid & + \\
\hline 5 & Tannin & ++ \\
\hline 6 & Saponin & + \\
\hline
\end{tabular}

\section{Results of TLC and HPTLC}

The spots obtained in TLC gives an idea about the plant constituents. The best separation was achieved using Toluene: Ethyl acetate: Formic acid in the ratio 6:3:1. The plates were first viewed through UV-fluorescence viewing cabinet $(365 \mathrm{~nm})$ and the Rf values of the spots were noted (Table No: 4). HPTLC was done and the HPTLC profile was shown in figure 4 and its 3D scan profile was shown in figure 5.

Table 4:- Rf values of spots obtained in Chromatography

\begin{tabular}{|l|l|l|l|}
\hline Solvent system with ratio & Sample & No of spots & Rf value \\
\hline & & & 0.84 \\
Toluene:Ethyl acetate: Formic acid. & Ethanolic extract of Acacia catechu & 3 & 0.75 \\
6:3:1 & & & 0.13 \\
\hline
\end{tabular}




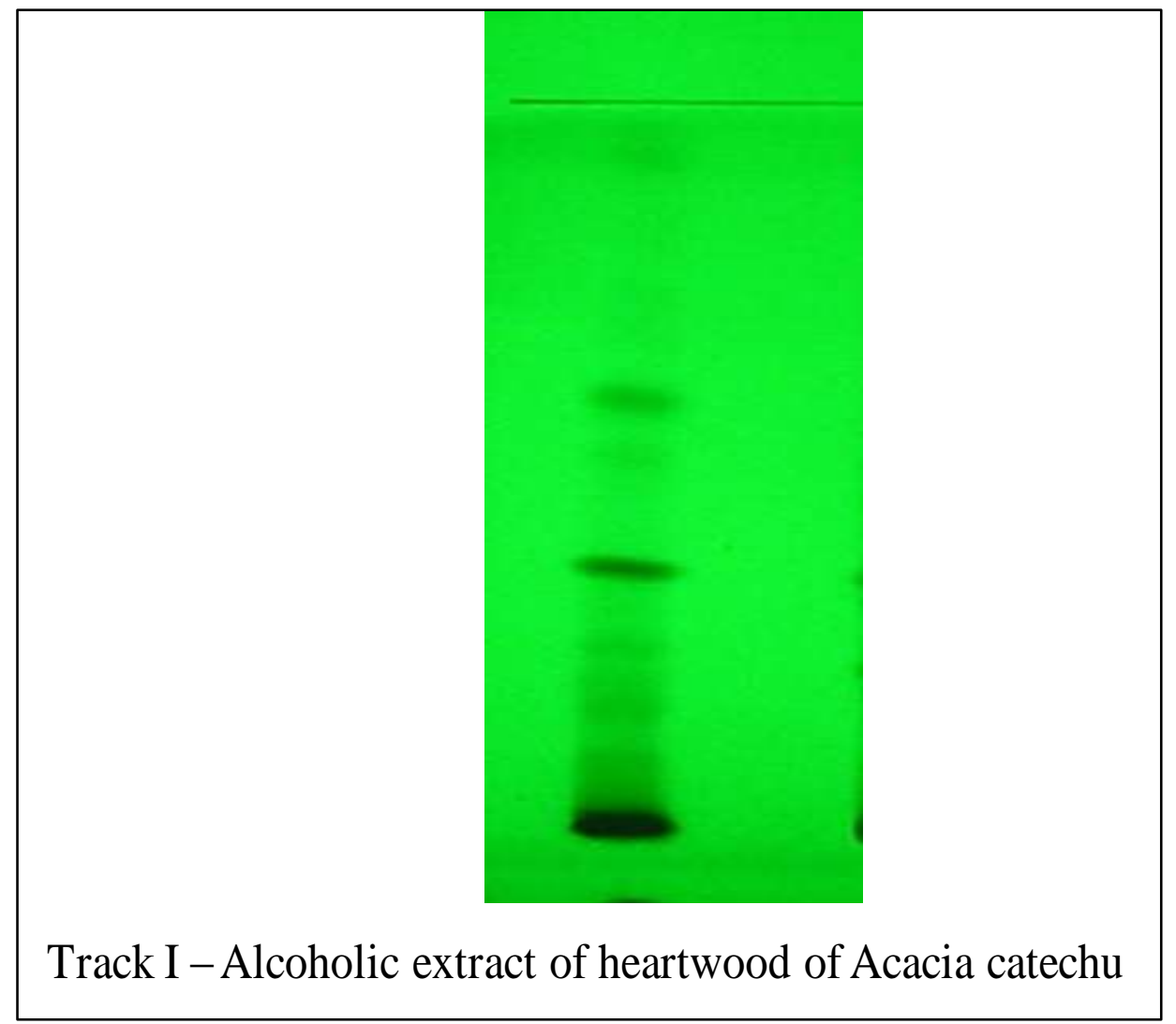

Figure 4:- HPTLC of heartwood of $A$ catech $u$ with solvent system Toluene:Ethyl acetate: Formic acid 6:3:1

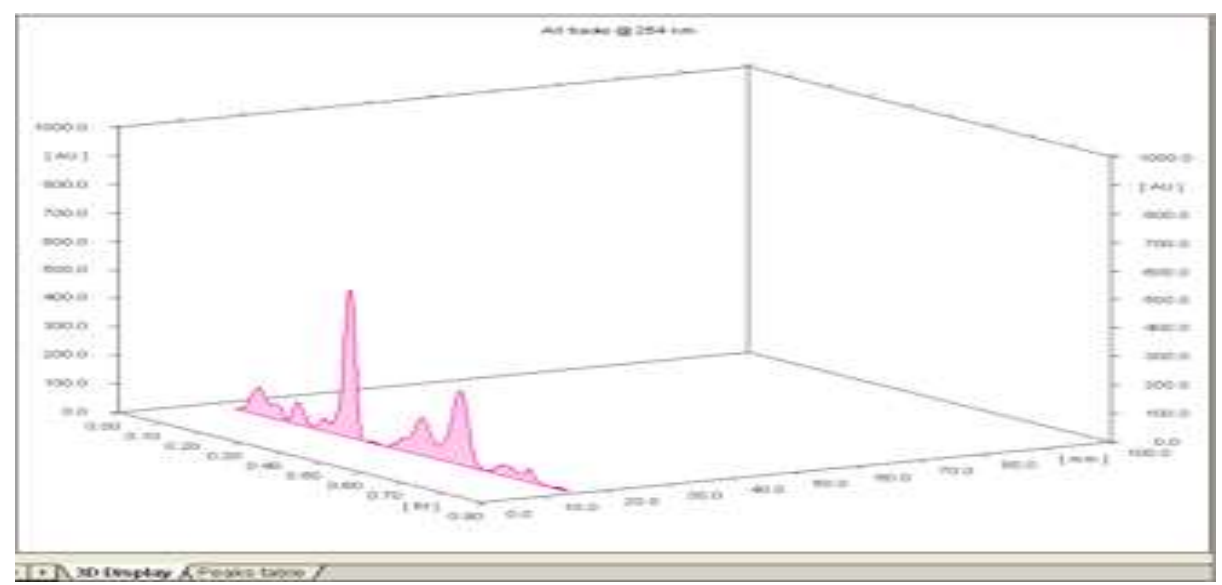

Figure 5: 3D scan profile of HPTLC of heartwood of A catechu with solvent system Toluene: Ethyl acetate: Formic acid 6:3:1 at $254 \mathrm{~nm}$

\section{Results of Atomic Absorption Spectroscopy}

Atomic absorption spectroscopy is used in the determination of heavy metal elements and some non-metal elements in atomic state and the results are shown in Table No: 5. Four heavy metals- copper, cadmium, iron and lead contents were analysed and found within permissible limits. Hence the drug is not contaminated by heavy metals and can be used safely for internal administration. 
Table 6:- Atomic absorption spectroscopy

\begin{tabular}{|l|l|l|l|l|}
\hline \multirow{2}{*}{ Samples } & \multicolumn{4}{l|}{} \\
\cline { 2 - 5 } & Cuvy metal concentration (in ppm) & Cd & Fe & Pb \\
\hline Heartwood of A catechu & $0.1323+/-$ & $0.1346+/-$ & $7.8888+/-$ & $0.0685+/-$ \\
& 0.004 & 0.012 & 0.061 & 0.043 \\
\hline
\end{tabular}

\section{Conclusion:-}

Macroscopy and microscopy along with the preliminary phytochemical evaluation of heartwood of $A$ catechu confirmed the identity, quality and purity of the plant. On physico chemical analysis the heartwood was found with water soluble extractive value higher than alcohol soluble extractive value (6\% and $1.5 \%$ respectively). The total ash value was $2.9 \%$. It showed high fibre content $(45.24 \%)$ The preliminary phytochemical screening showed the presence of different phytoconstituent groups such as flavonoids, saponins, alkaloids and tannins. AAS evidenced that the drug is not contaminated by heavy metals and can be used safely for internal administration. Here the observations and results obtained are useful for further pharmacological and therapeutical evaluation.

\section{Acknowledgement:-}

The authors are thankful to Department of Dravyagunavijnanam and Drug Standardisation Unit, Government Ayurveda College, Thiruvananthapuram for all the recordings made thereof.

\section{References:-}

1. Dash Bhagwan Vaidya, Sarma RK, editor. Agnivesa's Caraka Samhitha. Varanasi: Chaukhambha sanskrit series office; 2014. p. 93

2. Kirtikar \& Basu. Indian Medicinal Plants, Vol II. 2nd ed. New delhi. International book distributors; 2005 P 926

3. Pillai KVK ASG, editor. Sahasrayogam.30 ed.Alappuzha: Vidyarambham Publishers; 2011

4. C.K.Kokate, A.P.Purohit, S.B. Gokhale. Pharmacognosy. 50th. Pune; Nirali prakashan; 2014.1-15.

5. Indian Council of Medical Research. Quality Standards of Indian Medicinal plants Vol9. New Delhi.Indian Council of Medical Research;2011 p1-9

6. Anonymous. The Ayurvedic Pharmacopoeiaof India. Part-1, Vol. 3,Govt. of India.Ministry of health and Family welfare,Dept. of ISM\&H(AYUSH), New Delhi,2001, 227-40. 